\title{
Effect of laser texturing on the performance of ultra-hard single-point cutting tools
}

\author{
Priyanka Ghosh ${ }^{1} \cdot$ Manuela Pacella $^{1}$ (iD
}

Received: 26 September 2019 / Accepted: 10 December 2019 / Published online: 29 December 2019

(C) The Author(s) 2019

\begin{abstract}
This paper investigates the cutting performance and anti-adhesive properties of textured single-point polycrystalline diamond (PCD) cutting tools in machining Aluminium 6082 alloys. The micro/nano textures were first milled using a fibre laser (1064-nm wavelength) at different power intensities, feed speeds and pulse durations, and finally characterised using scanning electron microscopy, white light interferometry and energy dispersive X-ray spectroscopy. The effect of different textures on the cutting performance was investigated in turning tests under dry cutting conditions. The test was stopped at regular lengths of cut to allow analysis of height of adhesion through 3D white light interferometry. The data processing of the cutting forces and the microscopical characterisation of the tested cutting tools enabled the evaluation of the effects of texture design, friction coefficient and adhesive properties. The results indicated that feed force in tools with grooves perpendicular to the chip flow direction (CFD) was more stable $(20-40 \mathrm{~N})$ than the benchmark $(6-41 \mathrm{~N})$. Similarly, the thrust force for tools with grooves parallel to CFD and grooves perpendicular to CFD showed a homogeneous trend fluctuating between 60 and $75 \mathrm{~N}$ as compared with the benchmark (ranging between 73 and $90 \mathrm{~N}$ ). For texture depth in the order of $260 \mathrm{~nm}$ and post process roughness in the order of tens of nanometers, a reduction of average friction coefficient $(0.28 \pm 0.14)$ was reported when using lasered inserts with grooves parallel to the chip flow direction compared with the benchmark tools $(0.34 \pm 0.26)$ corroborated by reduced stiction of workpiece material on the rake face. In machining via textured tools with grooves perpendicular to CFD, the cutting forces were reduced by $23 \%$, and the surface quality of the machined workpiece was improved by $11.8 \%$, making this geometry the preferred choice for finishing applications. Using grooves parallel to CFD reduced the cutting forces by $11.76 \%$, adhesion by $59.36 \%$ and friction coefficient by $14.28 \%$; however, it increased the surface roughness of the machined workpiece, making this geometry suitable for roughing operations. For the first time, laser manufacturing is proposed as a flexible technique to functionalise the geometrical and wear properties of PCD cutting tools to the specific applications (i.e. roughing, finishing) as opposed to the standard industrial approach to use microstructurally different PCDs (i.e. grain size and binder \%) based on the type of operation.
\end{abstract}

Keywords Polycrystalline diamond insert $\cdot$ Laser surface texturing $\cdot$ Nanosecond pulse $\cdot$ Laser milling $\cdot$ Dry cutting $\cdot$ Cutting forces $\cdot$ Adhesion

\section{Introduction}

Aluminium alloys have become the most remarkably used alloys for the manufacture of aerospace components [1], in

Electronic supplementary material The online version of this article (https://doi.org/10.1007/s00170-019-04829-1) contains supplementary material, which is available to authorized users.

Manuela Pacella

M.Pacella@lboro.ac.uk

1 Wolfson School of Mechanical, Electrical and Manufacturing Engineering, Loughborough University, Loughborough, UK the automotive industry [2] and for machinery manufacturing [3]. In the precision machining of these alloys, cutting tools made of ultra-hard materials such as polycrystalline diamond (PCD) offer high wear resistance [4] due to their low friction coefficient, low chemical affinity, high thermal conductivity and inertness to high temperatures [5]. However, due to their low melting point [6], low hardness and high ductility [7], aluminium chips adhere strongly to the cutting tool causing early tool breakage [8]. For this reason, the major part of precision machining of aluminium alloys [5] still requires lubrication in practical use, contributing to environmental pollution. In fact, although cutting fluids reduce the friction in the tool-workpiece contact and decrease contact zone 
temperatures [9], they affect the environment and are difficult to dispose and recycle [7].

Furthermore, interest in dry machining has been increasing due to its ecological, cleaner production concept and economical impact in automotive and aerospace industries. Krolczyk et al. [10] reported that the ideal machining approach to decrease pollution is created by cooling, lubricating and reducing energy consumption in manufacturing processes. In their work, they focussed on dry cutting effects in turning of a duplex stainless steel using a coated carbide tool and they investigated the achieved surface roughness profiles, tool life, cutting forces, cutting energy and tool-chip friction coefficients. They observed a reduction in tool life by up to $65 \%$ when coolants were used. Although the application of cutting fluids during machining may cause a reduced temperature in the cutting zone, decreased cutting force and improved lubrication, previous research revealed that reduced energy consumption can be achieved in machining without cooling. Higher cutting temperatures would reduce the ductility of work material and tool-chip coefficient of friction thereby minimising the cutting forces and specific cutting energy values at low feed rate and high cutting speed, extending the tool life [11].

Due to the need of reducing the use of lubricants and stringent environmental regulations, the performance of dry machining of aluminium alloys attracted more attention in recent years. The viability of this process in reducing the total manufacturing costs, while the cost of cutting fluids was estimated to be approximately $16-20 \%$ of the total cost of manufacturing for the production industry [12]. However, dry machining has remained a real challenge for automotive, marine and aerospace engineering. Unfortunately, dry cutting via PCD cutting tools resulted in low machining efficiency and often the existence of early tool failure restricts the application of PCD commercially [13]. This is due to more friction, high adhesion between the tool and the workpiece and increased tool wear resulting in reduction of tool life [7, 14]. Saketi et al. [15] studied the wear and wear rate mechanisms of uncoated cemented carbide inserts in the turning of a Ti6Al4V alloy using a $6 \%$ solution of a semi-synthetic coolant, Hocut B50S with a $\mathrm{pH}$ of 9.5 and a flow rate of $200 \mathrm{~L} / \mathrm{min}$. They found that crater and flank wear of the inserts increased with increasing temperature at the cutting zone i.e. with increasing cutting speed and feed. They observed formation of build-up layer fragments of Ti6Al4V which was about $10-20 \mu \mathrm{m}$ in diameter in the chip surface using scanning electron microscopy (SEM) and energy dispersive X-ray spectroscopy (EDX). They also observed severe plastic deformation and macro cracking/fracture in the cutting-edge region due to combination of high cutting speed and feed. Krolczyk et al. [16] presented the attributes of cutting tools applied in the development of sustainable production strategies reporting that the effective influence of cutting conditions such as cutting speed, feed, tool materials and properties have not been yet fully recognised.
There have been a wide range of investigations on tool surfaces for improving the wear properties and controlling the adhesion of workpiece material to the cutting tool. Theoretical calculations [17] and experimental observations [18] for cutting tools have indicated that the tool's surface structure had a considerable effect on tribological performance during machining. Xing et al. [7] studied the effects of micro grooved cutting tools in various geometries to improve friction, anti-adhesive properties and wear behaviour in dry cutting of aluminium alloys using cemented carbide tools. They noticed that micro grooves on the rake face of the cutting tool reduced the cutting forces, improved anti-adhesion property and frictional behaviour at the chip-tool interface which in turn provided a smooth surface finish of the machined workpiece. They also found that the conventional tool increased both feed and main cutting forces with increasing cutting speed from 54.9 to $109.8 \mathrm{~m} / \mathrm{min}$ and a dramatical decrease when speed was increased to $439.2 \mathrm{~m} / \mathrm{min}$. However, all three textured tools reduced the feed and the main cutting forces at the speed of 54.9 and $109.8 \mathrm{~m} / \mathrm{min}$ and increased the same forces at the speed of $439.2 \mathrm{~m} / \mathrm{min}$ which indicated that the textured tools were effective in a certain range of cutting speeds. This was also found to have an effect in the friction coefficient.

Manufacturing of periodical micro/nano surface textures on the tool surface by various texturing techniques such as laser, electrical discharge machining, micro grinding, mechanical machining and chemical etching was reported $[19,20]$. Among the available manufacturing techniques, short pulsed laser micro-machining was found to be a versatile approach to generate precise micro-features and shown to be applicable for ultra-hard cutting tool materials without showing significant surface damage [20-22].

Sugihara and Enomoto [6] produced regular nano/micro grooves of depth in the range of $100-150 \mathrm{~nm}$ and $700 \mathrm{~nm}$ apart parallel to the main cutting edge on the rake face of a cemented carbide cutting tool using a femtosecond laser at a peak wavelength of $800 \mathrm{~nm}$. Their results showed that anti-adhesion improved with the textures parallel to the main cutting edge, but not satisfactorily on the cutting tool surface. A slight adhesion was still observed even after it was confirmed that regular nano/micro grooves were not buried by adhesion at a cutting length of $1800 \mathrm{~m}$. They found that adhesion would worsen at increased sliding distance possibly leading to tool breakage which in turn would possibly increase anti-adhesive effects. They also evaluated a diamond-like carbon (DLC) coated cutting tool with banded nano/micro grooves on the polished tool surface in a direction parallel to the main cutting edge (bands with $50-\mu \mathrm{m}$ width and 100-200-nm depth). DLC is an amorphous thin film comprising of different kinds of carbon-based materials and low friction coefficients, high hardness, high chemical stability and high wear resistance. They concluded that the newly proposed cutting tool improved anti-adhesive effects and lubricity of the cutting tool [23]. They later [24] investigated the performance of a 
cutting tool with micro stripe textured surface with grooves parallel to main cutting edge and grooves orthogonal to the main cutting edge to evaluate their anti-adhesive properties both in dry and wet cutting conditions. They found that the chip adhesion decreased even in dry cutting, but aluminium chip adhered strongly on the rake face as compared with the conventional benchmark tool. This was attributed to an increase of cutting temperature near the cutting edge of the conventional tool which exceeded the recrystallisation temperature of the aluminium alloy under dry cutting condition. Xing et al. [25] developed $\mathrm{Al}_{2} \mathrm{O}_{3} / \mathrm{TiC}$ cutting tools by a femtosecond laser on the rake face of the tool to improve anti-wear properties, and the cutting performance was compared in machining of AISI 1045. It was reported that the laser pre-treated tools improve the wear resistance and promote a small reduction in temperature. However, there was no significant difference in cutting forces as compared with conventional tools. Fang et al. [26] fabricated pyramid-like patterns with different shapes using a nanosecond laser. They recommended to employ a small laser fluence for the fabrication of more sophisticated profiles with small slope angles due to the melting phenomena becoming less visible with the increase in height and side length. However, morphological changes occurred in a different way at distinct positions depending on the dimension of the geometric features. Deng et al. [27] investigated the effects of nanoscale surface texturing on the rake face close to the main cutting edge of WC/Ti/Co carbide tools using a femtosecond laser for the textures manufacture. They found that cutting forces, cutting temperatures and tool-chip interface frictional coefficient were reduced significantly using tools textured on the rake face and tools previously coated with tungsten disulfide $\left(\mathrm{WS}_{2}\right)$. They conveyed that at high speed cutting $(250 \mathrm{~m} / \mathrm{min})$, the cutting forces were reduced by $13-22 \%$ using textured tools without coating and $25-44 \%$ using textured tools with $\mathrm{WS}_{2}$ solid lubricant coatings when compared with conventional tools. They reported an increase in cutting temperature with increasing speeds; however, the cutting temperature of the textured tools with and without coating was found to be reduced as compared with that of the non-textured tools. Ma et al. [28] numerically investigated the effects of micro groove width, edge distance and micro groove width-to-depth ratio on the cutting forces and chip formation of cemented carbide tool in dry 3D turning of titanium alloys. They summarised that the micro grooves with a $50-\mu \mathrm{m}$ width were effective in reducing cutting forces, which improved the frictional behaviour at the chip-tool interface. The results showed that the cutting force components were less than those of the regular tool, but all forces became larger than those of the regular tool when the micro groove width increased further from 90 to $120 \mu \mathrm{m}$. Kawasegi et al. [29] employed a femtosecond laser to develop either microscale or nanoscale textures on the rake face of the cutting tool to machine aluminium alloy A5052. They found that the cutting forces decreased with textures perpendicular to the polarisation direction; on the other hand, cutting forces for tools with parallel grooves were similar or slightly greater than the non-textured tools. Further, they conveyed that reduced cutting forces by $20 \%$ was due to corresponding reduction in the friction on the rake face. Obikawa et al. [30] experimentally investigated the effect of micro surface textures on the lubrication conditions at the tool rake face in machining aluminium alloys. They found that the parallel and the dot type micro-textures improved the lubrication conditions and reduced the friction force and the friction coefficient more effectively. Fatima et al. [31] developed structured tools with both rake and flank face structuring in the machining of AISI/SAE 4140. The total average reduction in main cutting force and feed force for structured cutting tool was found to be $10 \%$ and $23 \%$ respectively and the reduction in friction coefficient was found to be one of the reasons for the reduced main cutting and feed forces. They also found that at low speed, flank wear was low, but at a cutting speed of about $394 \mathrm{~m} / \mathrm{min}$, the wear was found to be increased. Xing et al. [32] produced structures on the rake face of ceramic tool in machining of AISI 1045 steel. Reduction in cutting forces by $15-20 \%$, temperature by $10-20 \%$ and coefficient of friction by $15-20 \%$ were observed. However, the surface roughness of machined workpiece was increased by the textured tools as compared with the nontextured tool. Sugihara and Enomoto [33] produced textures on the rake face and the flank faces of a WC-Co cemented carbide cutting tools to machine medium carbon steel. From the measurement of crater and flank wear on the cutting tools, it was found that the micro strips grooves on the flank face conveyed excellent flank wear resistance (reduction of 29\%), while rake face structured tool was effective in suppressing crater wear by $66 \%$.Although there are many studies on laser machining of brittle and hard materials, very few studies have been carried out on manufacturing surface textures on ultra-hard materials like PCD and comparing their cutting performance and wear mechanism with dry machining. Regardless of the evidence in the literature that textured tools improve cutting performance, the physical mechanisms involved are not well understood. The failure to design suitable geometries at the surface of the tool that influence the pressure distribution and cutting performance in an ideal way restricts the broad use of textured tools in industry. Existing research indicates that it is possible to use fibre laser for producing textures on the rake face of the ultrahard tooling materials to achieve the desirable benefits; however, not enough research has been carried out to investigate a correlation between the orientation of the grooves and the chip flow direction in dry cutting for precision machining of aluminium alloys. Cutting forces and tool wear are a good indication of performance as they directly affect cutting power [10]. For this research work, a relative investigation was done into the performance of textured tools in contrast with the benchmark.

In the need of reducing the use of lubricants, the objective of this paper is twofold: using a pulsed ytterbium-doped fibre laser (1064-nm wavelength, 70-W maximum output power), an experimental study is proposed to investigate the effect of 
programmable parameters and energetic conditions in microtexturing PCD turning inserts. Secondly, geometrically different designs are manufactured on PCD inserts to investigate the effect of texturing angle on the machinability, anti-adhesive properties, cutting forces and friction coefficient when machining aluminium alloys.

\section{Methodology}

\subsection{Materials}

The cutting tools used in the present study were commercially available PCD cutting tool inserts comprising of a diamond composite structure (average grain size of $10 \mu \mathrm{m}$ ) infiltrated by a cobalt binder (Co binder volume circa $10.3 \%$ ). The inserts were SPGN090308F in shape with a $0.5-\mathrm{mm}$ diamond layer directly synthetised on a tungsten carbide substrate $(1.1 \mathrm{~mm})$. The workpiece material selected for the turning tests was an aluminium alloy (6082) in the form of cylinders (80-mm diameter and length $150 \mathrm{~mm}$ ).

\subsection{Laser micro-nano processing design and manufacture}

The samples were processed using a 70-W Innolas MMS single mode SPI fibre laser (wavelength $\lambda=1060 \mathrm{~nm}$; pulse duration $\tau=260 \mathrm{~ns}$; and frequency $f=70 \mathrm{kHz}$ ). The cutting tool was clamped on a CNC translation stage. The laser machine was operated in pulse mode and delivered pulses based on direct modulation of the seed laser allowing programmed waveforms which are the results of an optimisation of the peak power at a specific pulse repetition rate. Beam diameter at the focal points was measured to be approximately $30 \mu \mathrm{m}$ to generate micro/nano grooves.

Several experiments were conducted to establish the correlation between laser energy and kinematic parameters and experimentally optimise the geometrical characteristics of the features produced namely the depth of the grooves and the surface roughness $(\mathrm{Ra})$ along the grooves. A preliminary step for the optimisation of the laser parameters was done due to the scarce knowledge of PCD composites in the laser machining process. The topographical analysis of the laser processed cutting tool and benchmark inserts before and after testing were measured using a 3D white light interferometer (Alicona Infinite Focus) with a vertical resolution of $110 \mathrm{~nm}$ and lateral resolution of $2.13 \mu \mathrm{m}$. Each sample was scanned, and three single profiles were extracted from top, bottom and centre of each area. For each sample, 2D roughness parameters namely Ra, Rz, Rq were obtained from the 3D white light interferometer and the average of the three areas of each profile was calculated. Figure 1 is an example of the method used for laser grooves depth optimisation and the corresponding white light interferometry measurements. The geometric details proposed by previous research [6] were used as an initial reference to select the depth of the grooves in the present study. After laser processing, the measurement of grooves was used for screening the processing parameters (laser power intensity, laser beam frequency and feed speed). An exploratory set of laser ablation trials were carried out changing the laser power intensity to understand the variation in the depth and the surface roughness parameters of the grooves produced.

The dependence of the depth is related to the thermal accumulation in the volume to be removed. Therefore, values with low depth and smooth surface were selected considering the correlation of ablation rate and thermal accumulation which also allows a precise material removal without any thermal damage and obtain a heat-affected zone (HAZ) free material removal. In dry cutting with higher depth of grooves, there is a possibility that the chips can be suppressed increasing aluminium stiction on the surface and the cutting forces. The laser parameters selected for the final design of experiment to perform laser processing of the PCD tools were feed speed of $900 \mathrm{~mm} \mathrm{~s}^{-1}$, intensity of $20 \%$, fluence of $3.38 \mathrm{~J} \mathrm{~cm}^{-2}$ and frequency of $70 \mathrm{kHz}$. The grooves were $260 \mathrm{~nm}$ in depth, $7 \mu \mathrm{m}$ in width and spaced at a pitch (centre to centre) of $20 \mu \mathrm{m}$. Three different types of texture designs were generated on the rake face of the tool: grooves perpendicular to the chip flow direction (CFD), grooves parallel to CFD (at an acute angle inclined to the direction of the chip flow) and grooves parallel to the main cutting edge (MCE) and the performance of these were benchmarked to a non-textured plain cutting tool.

Post-laser fabrication, residual debris was removed by ultrasonic cleaning of the manufactured samples in a methanolfilled glass vial for approximately $30 \mathrm{~min}$. A JEOL Zeiss SEM was used to perform imaging and chemical composition using energy dispersive X-ray spectroscopy (EDX). The mapping feature was used to determine any changes in chemical composition due to the machining.

\subsection{Turning test}

A three-axis machining centre (Haas TL-1 CNC lathe; max. spindle speed $1800 \mathrm{rpm}$; spindle power $30 \mathrm{~kW}$ ) was used to perform the cutting trials and the cutting forces were acquired at a sampling rate of $10 \mathrm{kHz}$. A specially designed fixturing system was manufactured to accommodate a three-axis dynamometer (Kistler Kiag Swiss 9257A) connected to three (one for each axis) charge amplifiers (Kistler 5015) and then to a data acquisition board (Picoscope PC Oscilloscope) and dedicated Picoscope application to save and process the signals. Monitored cutting forces namely feed force $\left(F_{\mathrm{c}}\right)$, tangential cutting force or thrust force $\left(F_{\mathrm{t}}\right)$ and radial force $\left(F_{\mathrm{z}}\right)$ and their respective directions are shown in Fig. 2. The inserts were 
(a)

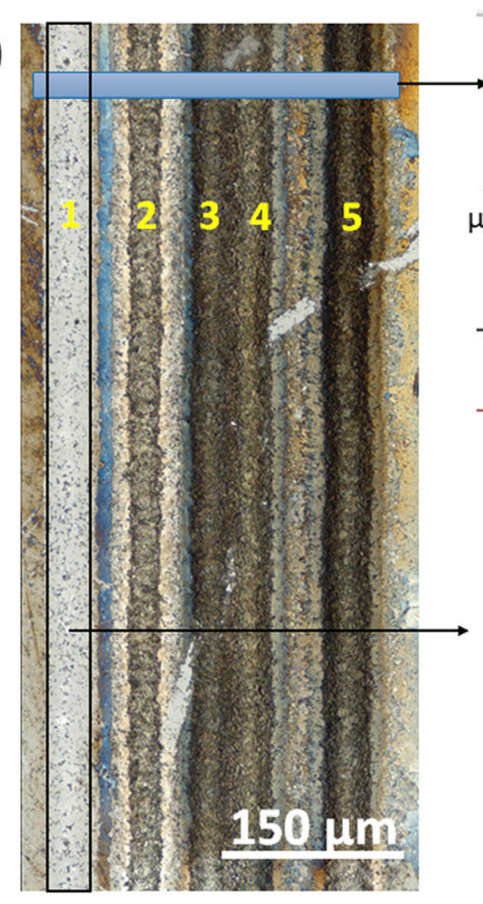

\section{Depth profile}

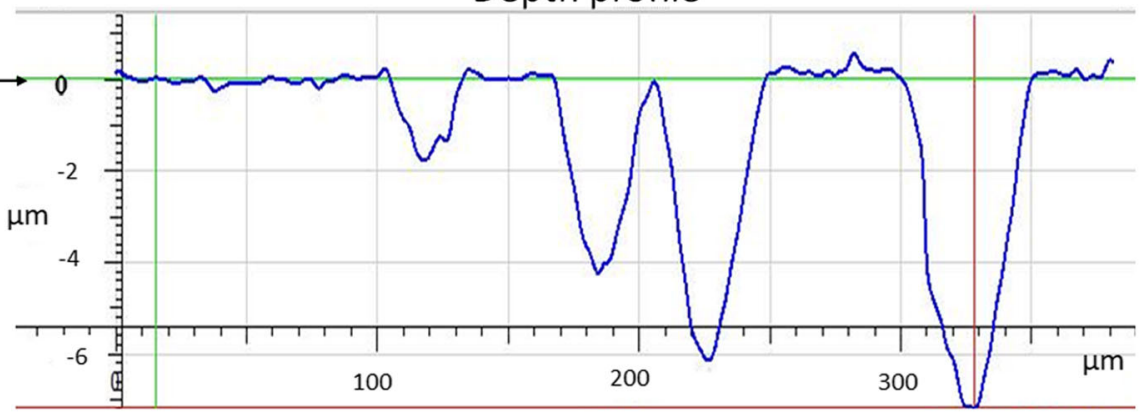

(b)

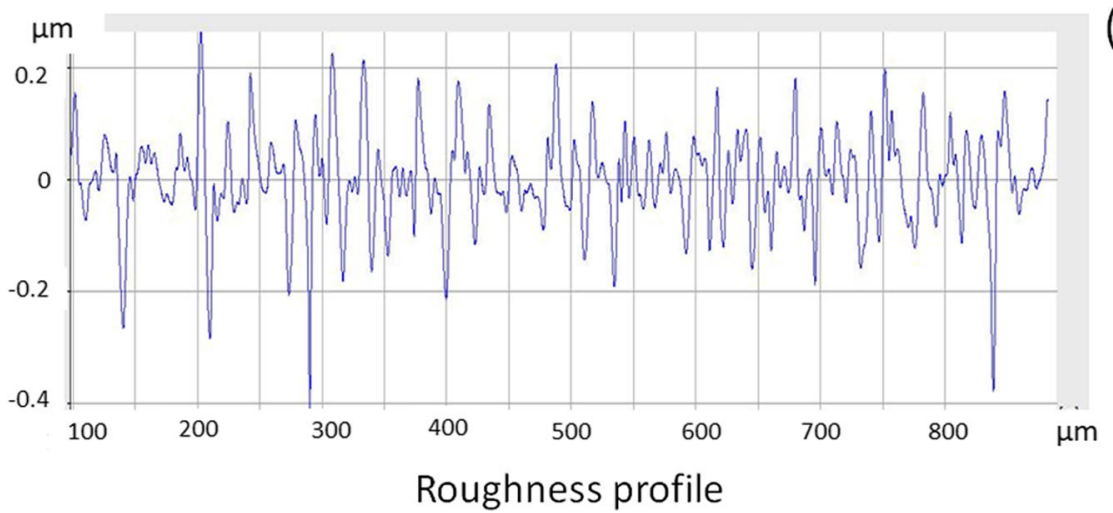

Fig. 1 Topographical profiles at feed speed $=900 \mathrm{~mm} \mathrm{~s}^{-1}$ and frequency $=70 \mathrm{kHz}$ : a varying intensity at intervals of $20 \%$ (from $20 \%$ in area 1 to $100 \%$ in area $5, \mathbf{b}$ depth profile at $20 \%$ intensity and $\mathbf{c}$ roughness profile at $20 \%$ intensity

hold using a commercial tool holder with a rake angle of $8^{\circ}$. The experimental setup of the cutting process and the direction of the textures were defined relative to the chip flow direction and the main cutting edge. All the longitudinal cutting trials on $\mathrm{Al}$ alloy 6082 were performed under dry cutting conditions with a depth of cut of $1 \mathrm{~mm}$, feed rate of $0.1 \mathrm{~mm} /$ rev and cutting speed of $250 \mathrm{~m} / \mathrm{min}$.

The machining was stopped every 100 -mm length of cut to enable evaluation of the wear progression. Monitoring of the cutting forces permitted to calculate the average and the maximum forces from the voltage versus time domain from the PicoScope software. By default, a PicoScope measured the voltage outputs and further data processing was needed to extract the forces as well as friction ratio. The output sensitivity was set for $200 \mathrm{~N} / \mathrm{V}$ for radial force, $200 \mathrm{~N} / \mathrm{V}$ for feed force and $100 \mathrm{~N} / \mathrm{V}$ for thrust force on the respective charge amplifier.
Friction at the tool-chip contact area plays a vital role in tool wear and cutting forces: the ratio of the forces depends on the coefficient of friction; thus, high friction results a very high wear rate [34]. To reduce the tool wear, process parameters were used for an efficient cutting process by evaluating the tribological conditions at the interfaces. The average friction coefficient of the tool-chip interface was calculated with the measured forces based on equation [31] expressed in (1):

$\mu=\frac{F_{\mathrm{t}} \sin \alpha+F_{\mathrm{c}} \cos \alpha}{F_{\mathrm{t}} \cos \alpha-F_{\mathrm{c}} \sin \alpha}$

where $\mu$ is the friction coefficient, $\alpha$ is the rake angle and $F_{\mathrm{t}}$ and $F_{\mathrm{c}}$ are the thrust force and feed force respectively. Diamond typically exhibits a low friction coefficient and high wear and erosion resistance.
Fig. 2 Experimental setup of the turning tests showing cutting forces: Fc, feed force; Fz, radial force; and Ft tangential cutting or thrust force

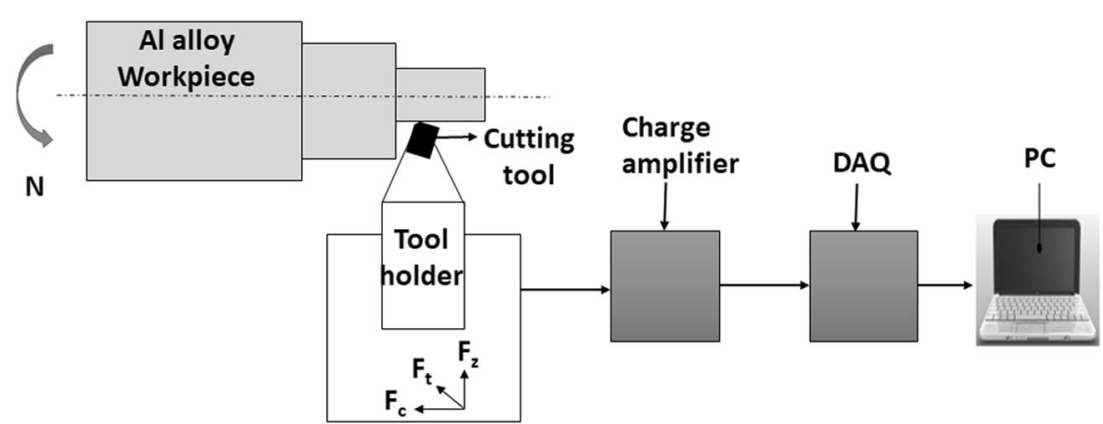




\subsection{Characterisation of tested tools and workpiece material}

The wear of all the tested tools was measured at specific lengths of cut to allow comparison in performance progression between reference results (benchmark) and textured cutting tools. The flank and crater wear were measured by $3 \mathrm{D}$ white light interferometry and scanning electron microscopy (SEM). Kumel et al. $[35,36]$ established that the determination of the flank, crater and the corner radius wear length are the important factors to assess the tool life and surface quality of machined surfaces. SEM-EDX chemical analysis was used to measure the adhesion of $\mathrm{Al} 6082$ on the rake and flank faces of the tools.

Arithmetic mean deviation of the roughness profile (Ra), maximum height of roughness profile (Rz) and total height of roughness profile (Rt) averaged for each workpiece were examined after a cutting length of $2.758 \mathrm{~km}$ using the standard measurement techniques of the stylus-based instruments named FormTalysurf 50 using the standard cut off and filter mentioned in the Good Practice Guide No 37 specified by the National Physical Laboratory (NPL) document [37] and were extrapolated based on ISO 13565.

\section{Results and discussion}

\subsection{Effect of laser micro-nano manufacturing on the topography of cutting tool}

The surface roughness of the lasered tools was measured to investigate how it was affected by the change in power intensity. Figure 3 shows the variation of depth and surface roughness parameters namely the arithmetic mean deviation of the roughness profile (Ra), the root-mean-square deviation of the roughness profile $(\mathrm{Rq})$ and the maximum height of roughness profile $(\mathrm{Rz})$ with respect to laser power intensity at a feed speed of $900 \mathrm{~mm} / \mathrm{s}$ and a frequency of $70 \mathrm{kHz}$. A sharp rise in $\mathrm{Ra}$ and $\mathrm{Rq}$ was observed when the intensity was increased from 20 to $40 \%$ (at 70-W maximum output power), while the relationship seemed to stabilise above $40 \%$. The best roughness profile was achieved through a low-energy ablation at a fluence of $3.38 \mathrm{~J} \mathrm{~cm}^{-2}$. The depth of the grooves was found to be increased from 0.261 to $7.234 \mu \mathrm{m}$ when the intensity was increased to $100 \%$ intensity and increased heat-affected zone (HAZ).

Grooves manufacturing using laser intensities above $40 \%$ resulted in material removal through evaporation and sublimation [38] causing material damage in the form of a heataffected zone (HAZ). Variation of feed speed also affected the surface roughness in accordance with previous research [39] where it was found that the PCD material have longer exposure time to absorb the laser irradiation at slower processing conditions $\left(70 \mathrm{~mm} \mathrm{~s}^{-1}\right)$ causing a conversion of the absorbed energy into thermal energy, the transformation of metastable diamond into stable graphite and the expansion of the melting cobalt on the diamond grains. In this work, the selected speed (900 $\mathrm{mm} \mathrm{s}^{-1}$ ) allowed to decrease the energy absorption and conversion and avoid the formation of residual stresses typical of polycrystalline diamond (Co binder volume circa 10.3\%) reported in previous research [39].

Optimisation of the necessary laser intensity to achieve features in the order of $200 \mathrm{~nm}$ was carried out and Fig. 4 shows the results obtained through nanosecond laser processing at $20 \%$ laser intensity (70-W maximum output power) with the direction of the surface textured grooves on the rake face of the cutting tools.

For the considered PCD material, a low-energy ablation (fluence $=3.38 \mathrm{~J} \mathrm{~cm}^{-2}$ ) is the required manufacturing process to achieve repeatable nanoscale grooves with low depth and smooth surface finish.

\subsection{Turning tests}

\subsubsection{Cutting forces monitoring}

Monitoring of feed, thrust and radial forces showed a homogeneous trend for each of the tested samples, allowing to evaluate the machinability of the surface textured and the benchmark tools. Figures 5 and 6 show the comparison of the monitored cutting forces for the three designs and benchmark tools up to a sliding distance of $2.758 \mathrm{~km}$. The maximum and the average forces were exported from the saved signals in the PicoScope software for the entire process. Each value shown in Fig. 5 is the average of maximum and average forces measured during the entire process. It was observed that the radial forces for the tool with grooves parallel to CFD oscillated between 18 and $58 \mathrm{~N}$. It was also noted that the fluctuation of the radial force in the cutting process with the textured tools was smaller compared with the benchmark. Similar to radial forces, reduction in feed forces and thrust forces was also brought by textured tools at different lengths of cut. It was found that the cutting forces with grooves parallel to CFD were more stable (Fig. 5), and the average cutting forces were lower compared with the benchmark. The feed force of the benchmark was found to be increased from 5.8 to $40.7 \mathrm{~N}$ at a cutting distance of $2.374 \mathrm{~km}$ and then decreased dramatically with the increase in length of cut. On the other hand, the textured tools showed a stable trend in feed force which varied between 20 and $30 \mathrm{~N}$ in increasing sliding distance from 1 to $2.758 \mathrm{~km}$. Similarly, the thrust force for tool with grooves parallel to CFD and grooves perpendicular to CFD showed a homogeneous trend fluctuating between 60 and $75 \mathrm{~N}$ as compared with the benchmark (ranging between 73 and $90 \mathrm{~N}$ ).

The plots in Fig. 5 indicate that the design of textures has a significant effect on the measured forces, and that low 


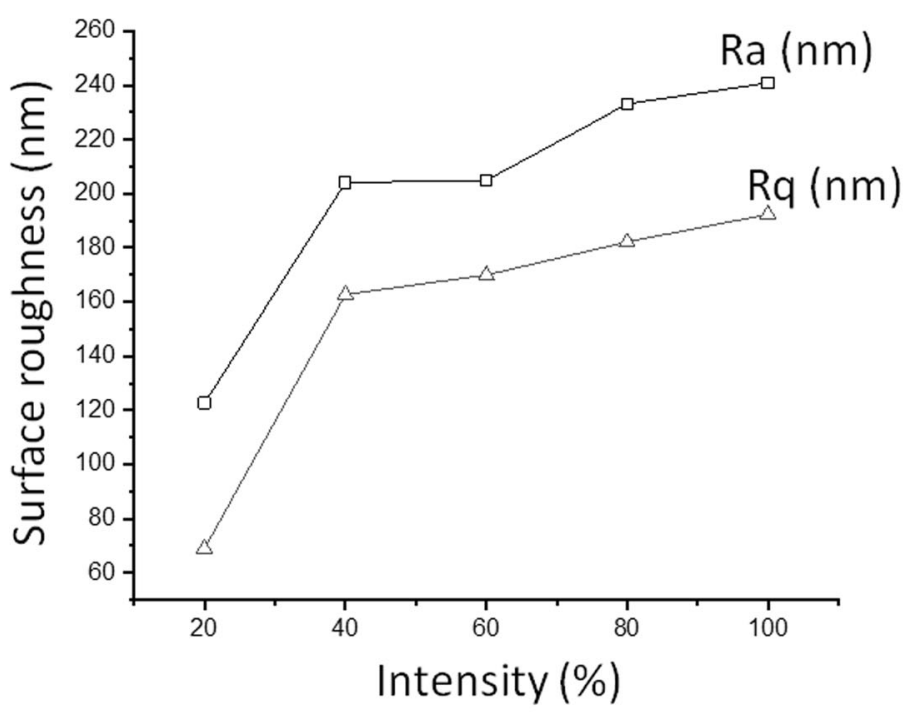

(a)

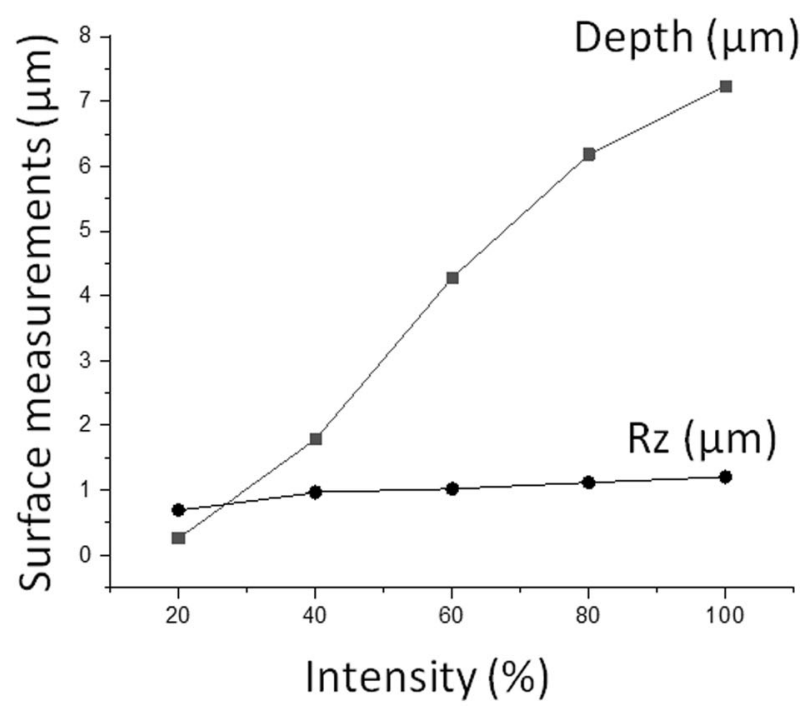

(b)

Fig. 3 Effect of process parameters on the surface topography of the cutting tool: a dependence of surface roughness Ra and Rq on intensity and $\mathbf{b}$ dependence of maximum height of roughness profile and depth versus intensity

variation of feed and radial forces can be achieved with microtextured PCD tools under dry cutting conditions. These results revealed that the structured tools improved the machinability of cutting forces and the direction of the grooves had shown little effect on the cutting forces as compared with the benchmark, which is in line with results from previous research [29]. The thrust force was found to be decreased when the texture direction was perpendicular; on the other hand, thrust force was similar or slightly smaller than that of the benchmark when the texture direction was parallel to chip flow direction and parallel to main cutting edge. This results are in accordance with the findings of Kawasegi et al. [29].

Figure 6 shows the standard deviation of the average and the maximum forces during machining process up to a sliding distance of $2.758 \mathrm{~km}$. The error bars represent the fluctuation of the forces of textured tools, which were smaller compared with the benchmark, indicating that the textured tools led to a more stable cutting process. This might be due to the cutting speed which seems to have a profound effect on the cutting forces monitored while machining. Although the effects in reducing tool temperature are typically noticeable at low cutting speeds as compared with high speeds, the machining results proposed in this paper revealed that at high cutting speed $(250 \mathrm{~m} / \mathrm{min})$, a reduction of cutting forces can be achieved for textured tools as compared with the benchmark. These results are in accordance with Deng et al. [27] and Xing et al. [7].

The comparison of feed and radial forces revealed that the textured tools with grooves in the direction perpendicular to CFD and parallel to CFD were effective in a range of 20 $40 \mathrm{~N}$ when benchmarked to conventional cutting tools (20 to $60 \mathrm{~N}$ ), while the thrust force for the tool with textures parallel to CFD showed intermittent variations (i.e. 62 to $85 \mathrm{~N}$ ) but still lower forces were achieved compared with the benchmark (i.e. 75 to $92 \mathrm{~N}$ ). The obtained results revealed a reduction of cutting forces for all the lasered inserts;
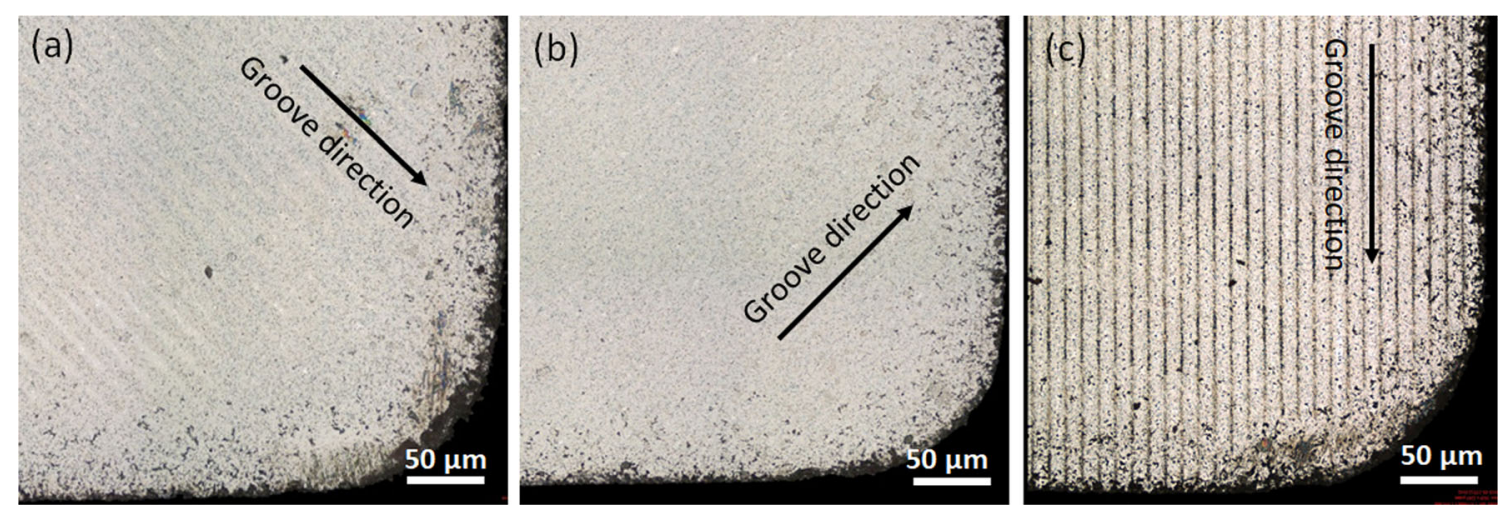

Fig. 4 Micro-nano laser processed samples: a optical microscopy of grooves parallel to CFD, $\mathbf{b}$ grooves perpendicular to CFD and $\mathbf{c}$ grooves parallel to MCE 


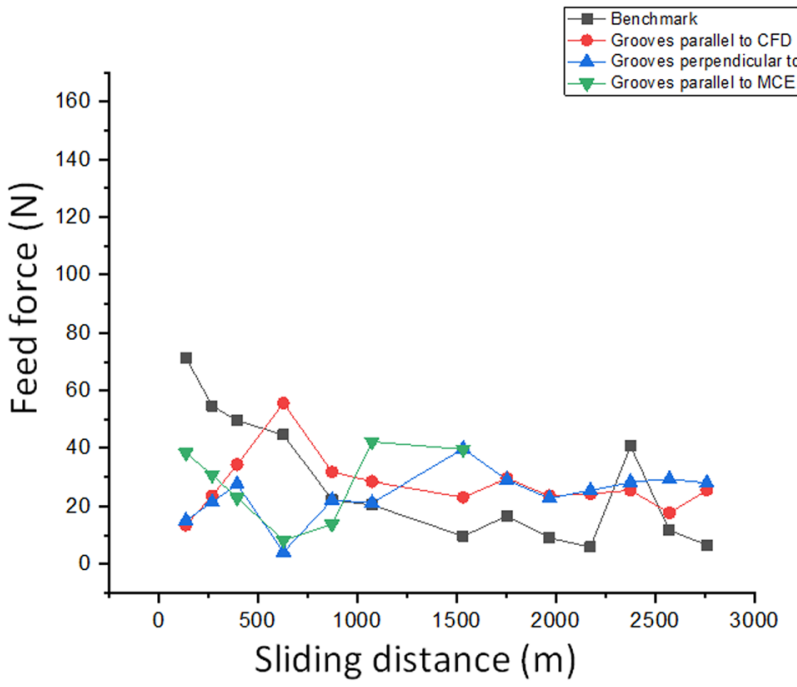

(a)

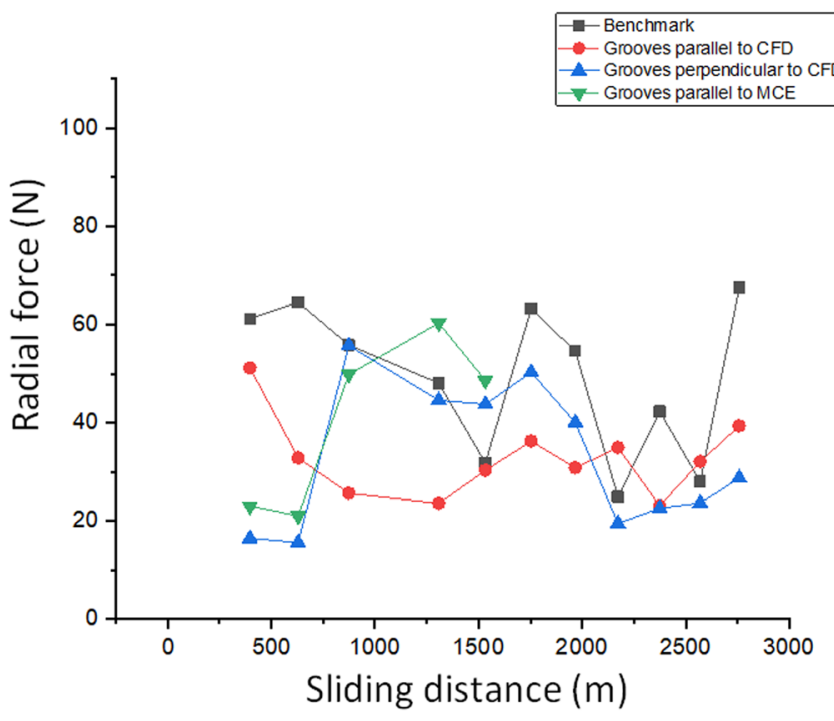

(b)

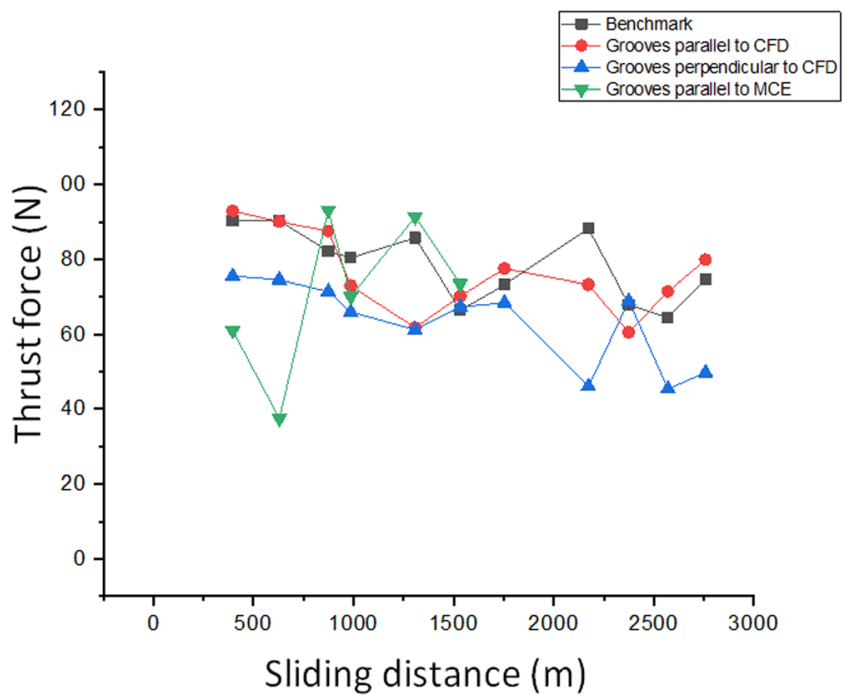

(c)

Fig. 5 Comparison of the acquired forces while using textured tools and a benchmark cutting tool: $\mathbf{a}$ feed force, $\mathbf{b}$ radial force and $\mathbf{c}$ thrust force

however, for inserts with grooves parallel to CFD and grooves parallel to MCE, a high scatter of forces was found (Fig. 6c). This might be due to the direction of structures produced on the rake face of the tool which seems to affect the cutting performances of the textured tools and the machinability of the workpiece. The textures helped to reduce the friction between the tool-workpiece contact area reducing the contact zone temperature, which in turn reduced the cutting forces. The grooves parallel to MCE caused the chips to stick on the cutting-edge forming chipping, causing higher variability of forces. According to the results obtained, it was found that particular texture patterns in the rake face were effective to reduce the tool-chip contact area influencing the cutting performances. These results are well in line with the findings of Kawasegi et al. [29].

\subsubsection{Friction coefficient at the tool-chip interface}

Figure 7 shows the friction coefficient at the tool-chip interface of the lasered tools and the benchmark, which was calculated using Eq. (1). Average thrust force (Fz) and average feed force $(\mathrm{Fc})$ were used to calculate the friction coefficient up to a sliding distance of $2.758 \mathrm{~km}$. The range of the friction coefficient for the insert with grooves parallel to CFD was found to be ranging between 0.14 and 0.42 compared with the benchmark (0.08 to 0.6$)$, while the friction coefficient for textured grooves perpendicular to CFD showed intermittent variation of about 0.14 to 0.65 (higher friction coefficient range) compared with the benchmark. The tool with grooves parallel to MCE showed the worst friction coefficient variation. Although $25-75 \%$ of the variation for the tool with grooves 


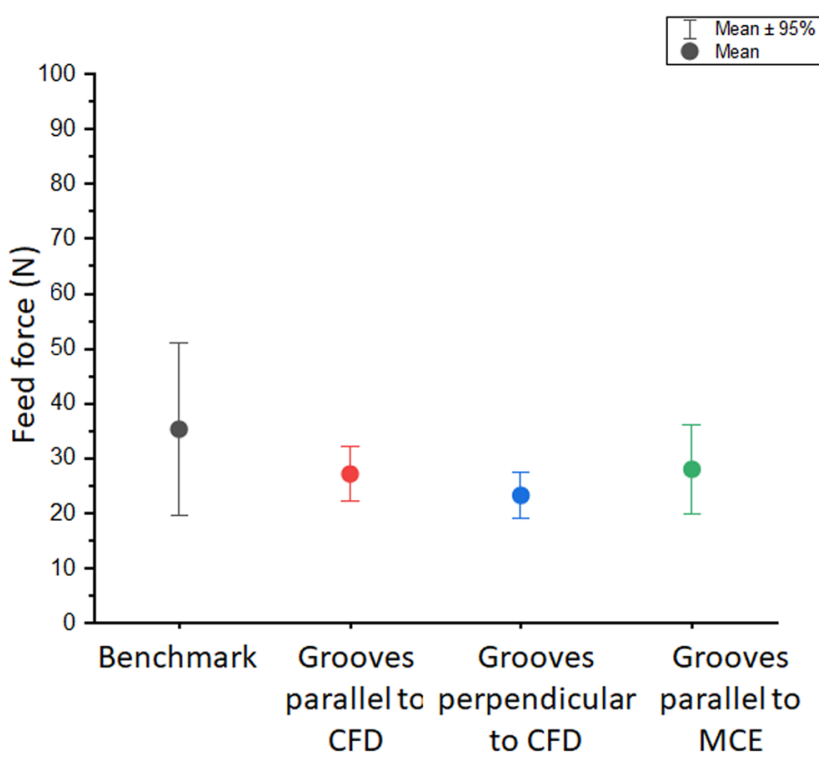

(a)

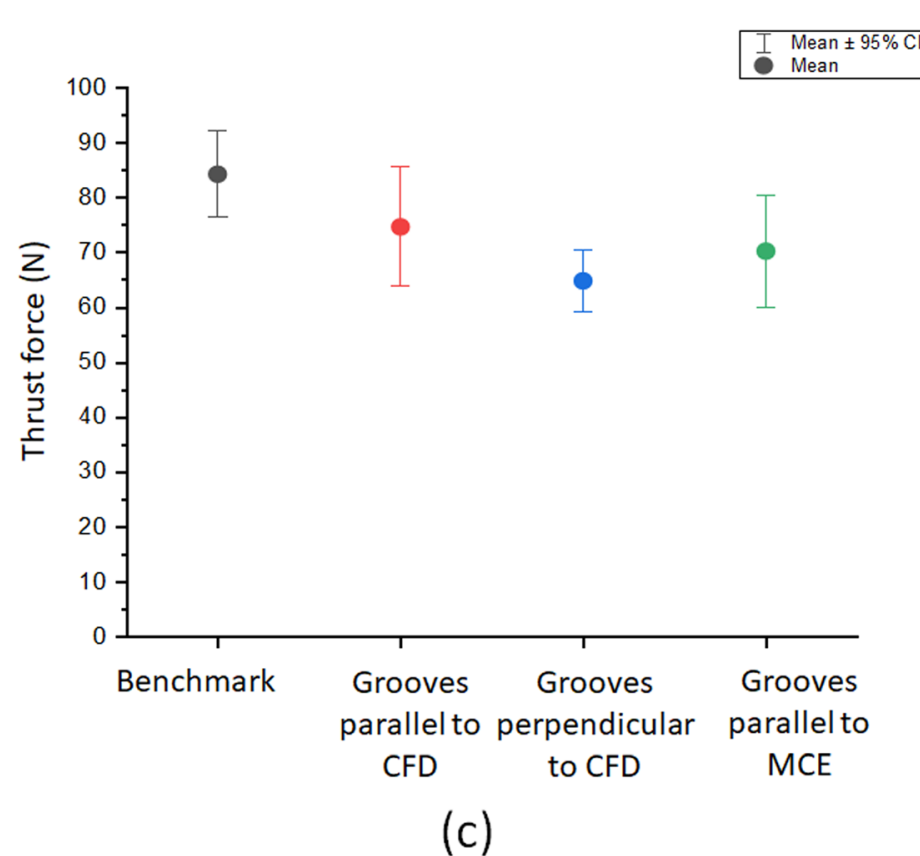

(c)

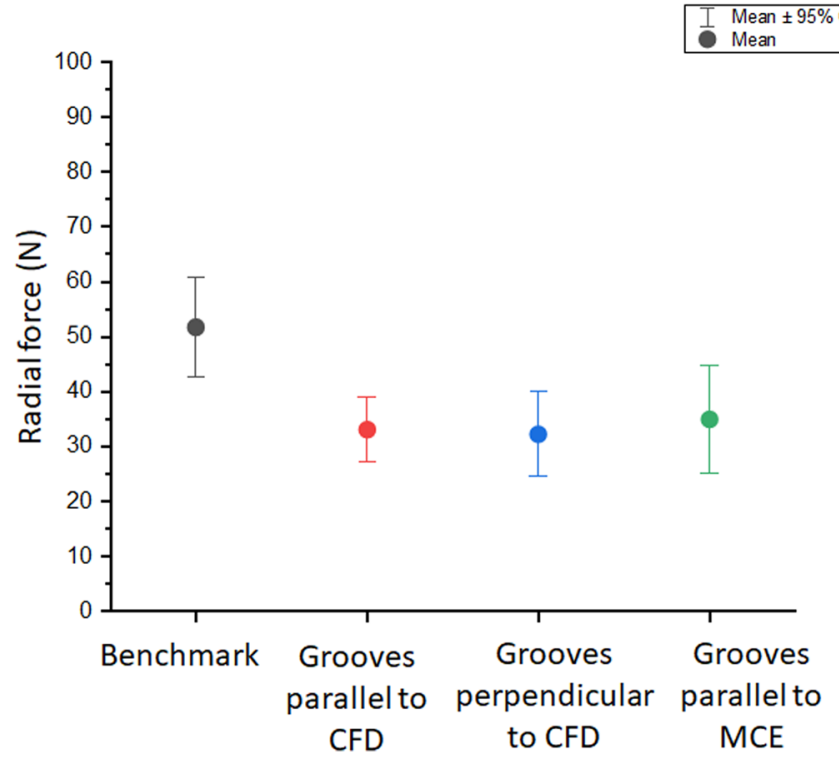

(b)

Fig. 6 Interval plots of maximum and average forces of the benchmark and the micro-textured tools at a sliding distance of $2.758 \mathrm{~km}$ : $\mathbf{a}$ feed force, $\mathbf{b}$ radial force and $\mathbf{c}$ thrust force

perpendicular to CFD showed up to be ranging from 0.3 to 0.5 , the overall range showed higher values of friction coefficient compared with the benchmark. The reduction of friction coefficient for the tool with grooves parallel to CFD at the chip-tool interface appears to be the main reason in the variations of the thrust force as compared with the benchmark tool. This is most likely due to the difference in friction mechanism and a possible anti-adhesion effect at the tool-chip interface as shown in Fig. $8 \mathrm{c}$ and d. These results are in accordance with the findings of Sugihara and Enomoto [6].
Figure 8 shows the top view of the benchmark and textured cutting tools after the machining tests and results from the EDX chemical analysis. No indications of considerable crater wear can be seen. Rather, geometrical differences between the textured tools and the benchmark can be observed as a result of adhesion height on the rake face of the cutting tools. The chips resulting from both the benchmark testing, and the textured tools with grooves perpendicular to CFD and with grooves parallel to MCE, were more easily adhered towards the rake face. EDX results for the benchmark tool (Fig. 8a, b) 


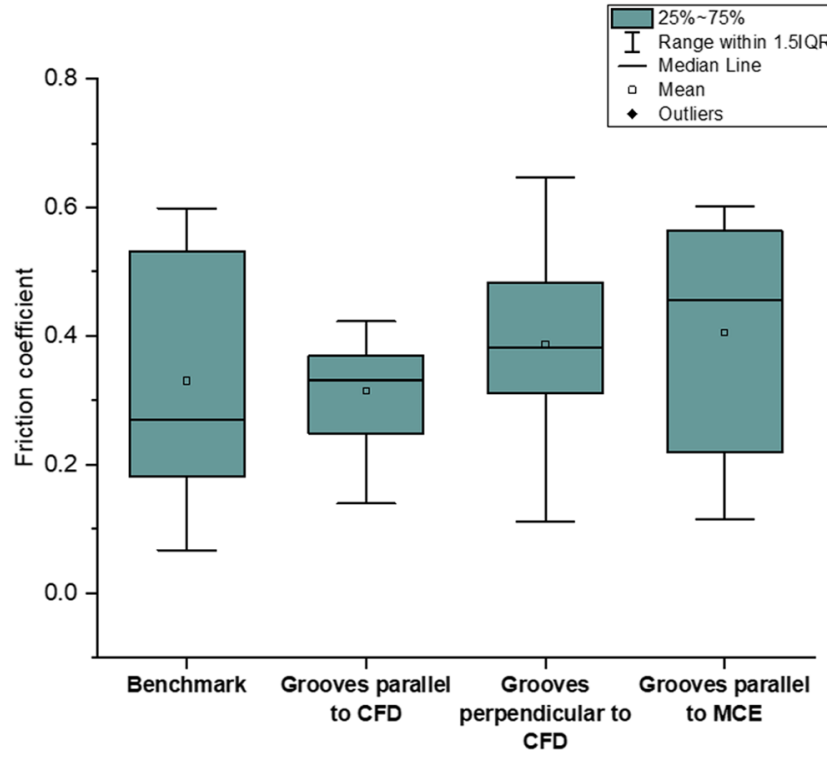

Fig. 7 Average value of the coefficient of friction calculated from the cutting forces data for all types of machining cases benchmark, grooves parallel to CFD, grooves perpendicular to CFD and grooves parallel to MCE

and cutting tool with grooves perpendicular to CFD (Fig. $8 \mathrm{e}, \mathrm{f})$ showed large aluminium adhesion on the rake face. The red area in Fig. 8 a shows a deposited layer of $37.6 \mu \mathrm{m}$ for the benchmark tool, whereas Fig. $8 \mathrm{c}$ and $\mathrm{g}$ show adhesion height of $15.28 \mu \mathrm{m}$ for tools with grooves parallel to CFD and $21.55 \mu \mathrm{m}$ for tool with grooves parallel to MCE. The degree of adhesion for tools with grooves perpendicular to CFD as shown in Fig. 8 e becomes higher $(49.27 \mu \mathrm{m})$ compared with the benchmark $(37.6 \mu \mathrm{m})$. The latter result is in accordance with previous research which revealed that nano-/micro-texture on the cutting tool surface increased the adhesion of aluminium chips to the surface in dry cutting [24]. It is also expected that grooves parallel to the CFD would promote chip escape through the grooves; however, the experiments carried out in this paper revealed that the mechanism for chip formation and chip flow would depend on the structures and the direction of the grooves. Textures parallel to CFD (Fig. $8 \mathrm{c}, \mathrm{d}$ ) and textures parallel to the MCE (Fig. 8g, h) reduced the extent of workpiece stiction at the rake face of the tool compared with the benchmark and the other tested tools. This finding may be attributed to the fact that the tool-chip contact area is reduced due to the structures being parallel to the chip flow. The reduction in adhesion promoted a decreased cutting temperature inducing the chip to flow faster and reducing plugging of the textures (Fig. 8c, d) possibly limiting the micro grooves to act as a micro-trap for wear debris. The improvement of friction behaviour was also validated by the friction coefficient calculations (Fig. 7). On the other hand, the reason behind the increased friction for tools with grooves perpendicular to CFD can be explained considering that at a cutting speed of $250 \mathrm{~m} / \mathrm{min}$ the workpiece material softened
Fig. 8 Left images depict the three-dimensional surface topography of the adhesion, and right images depict the SEM/EDX chemical analysis of the rake face at $2.758 \mathrm{~km}$ : benchmark tool (a) and (b); tool with grooves parallel to CFD (c) and (d); tool with grooves perpendicular to CFD (e) and (f); tool with grooves parallel to MCE (g) and (h)

due to the high cutting temperatures which in turn decreased the yield strength of the chip. Thus, the chip flows over the rake face of the tool resulting in higher friction coefficient as compared with the benchmark. In the case of tools with grooves perpendicular to the chip flow direction, the effect of the direction of textures on anti-adhesion properties led to the deposition of the chip adhesion along the grooves and increased the adherability on the rake surface. In the case of tools with grooves parallel to CFD direction, the grooves divided the adhesion area against the chip flow direction leading to prevent the chip adhesion from depositing and growing.

The detailed observation of the results showed that the tool with grooves perpendicular to CFD affects material adhesion as well as friction coefficient on the rake face. However, the grooved tools led to a lower cutting force.

The formation of built-up edge (BUE) and chipping on the rake face in machining of aluminium alloys make the machining process difficult resulting in poor surface finish [23, 30]. When the soften chips are held into the textures (Fig. 9a), the sharp edges of the textures can act as cutting edges creating a secondary cutting force on the chip and thereby causing a high friction coefficient. In addition, major changes of the cutting edges' geometries can be seen on the tool with textures parallel to MCE due to chipping as shown in Fig. 9b, which also corresponds to an increase in friction coefficient depicted in Fig. 7. The formation of BUE could break off the tool causing tool chipping, increasing the workpiece surface roughness and affecting the dimensional accuracy [40]. These results indicate that the direction of grooves in the textured tools were strongly affected by the high cutting speed (i.e. $250 \mathrm{~m} / \mathrm{min}$ ) as mentioned by Xing et al. [7].

\subsubsection{Surface roughness of the machined workpiece}

The roughness of the machined surfaces was measured to investigate how it was affected by the geometrically different surface textures manufactured on the rake face of the cutting tools. Figure 10 shows the workpiece surface roughness (Ra, $\mathrm{Rz}$ and $\mathrm{Rt}$ ) for the benchmark and the textured tools measured based on ISO 13565.

The parts machined with a cutting tool having grooves perpendicular to CFD revealed the lowest values of $\mathrm{Ra}, \mathrm{Rz}$ and Rt, respectively, $1.2963 \mu \mathrm{m}, 6.1055 \mu \mathrm{m}$ and $6.3592 \mu \mathrm{m}$, while the tool with grooves parallel to CFD resulted in increased values of roughness $(\mathrm{Ra}=1.845 \mu \mathrm{m}, \mathrm{Rz}=$ $10.534 \mu \mathrm{m}, \mathrm{Rt}=11.12 \mu \mathrm{m})$ at the workpiece when compared with the benchmark $(\mathrm{Ra}=1.47 \mu \mathrm{m}, \mathrm{Rz}=7.85 \mu \mathrm{m}, \mathrm{Rt}=$ 

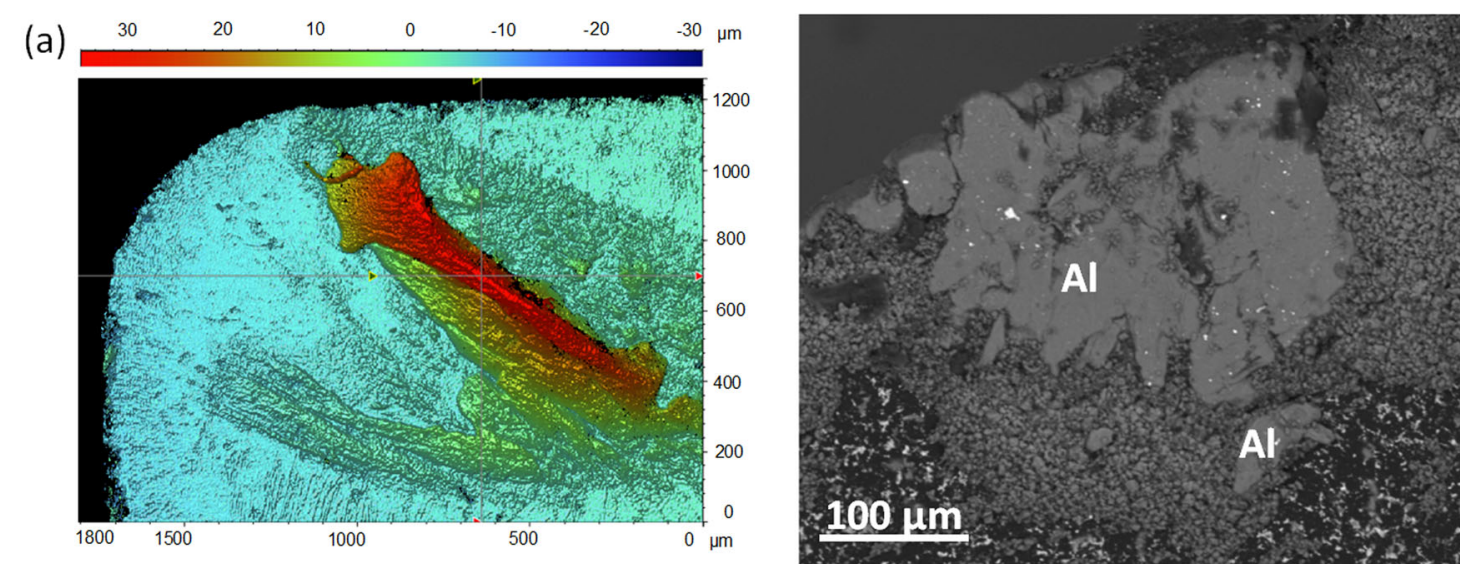

(b)

(c)
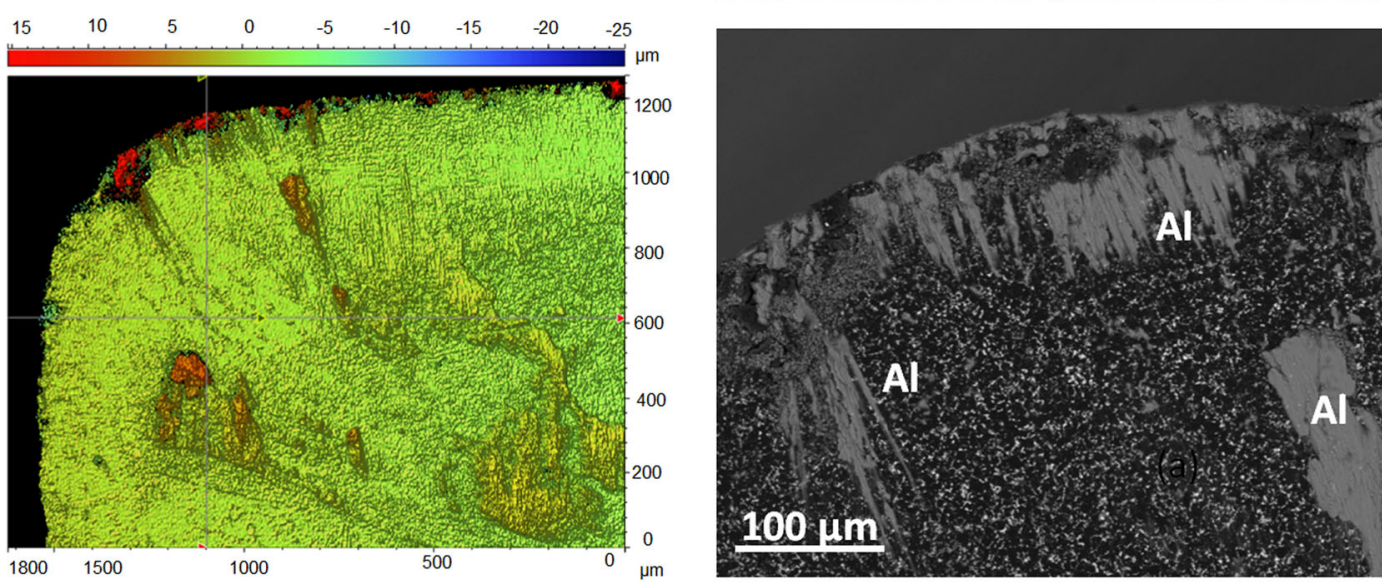

(d)

(e)
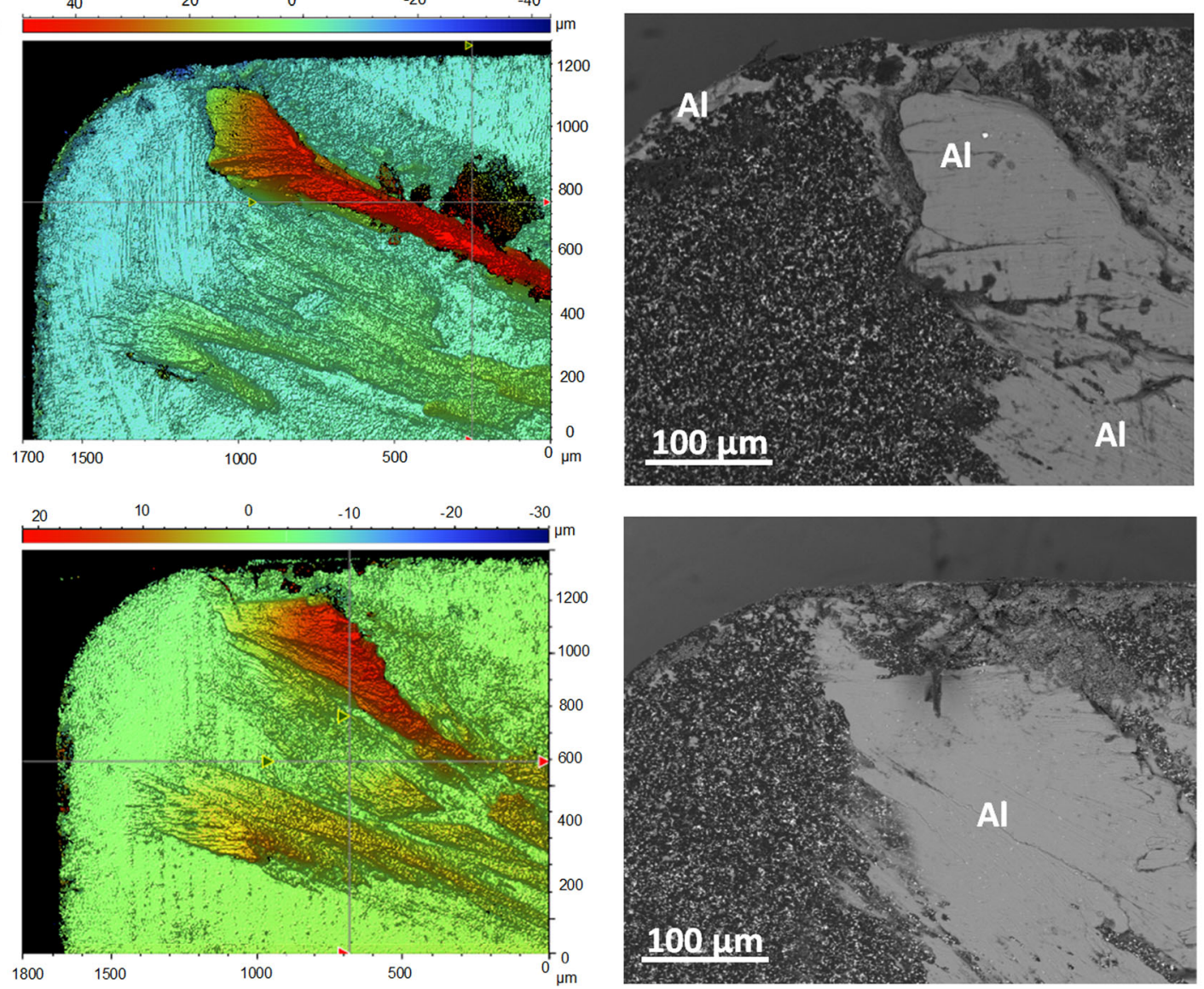

(g)

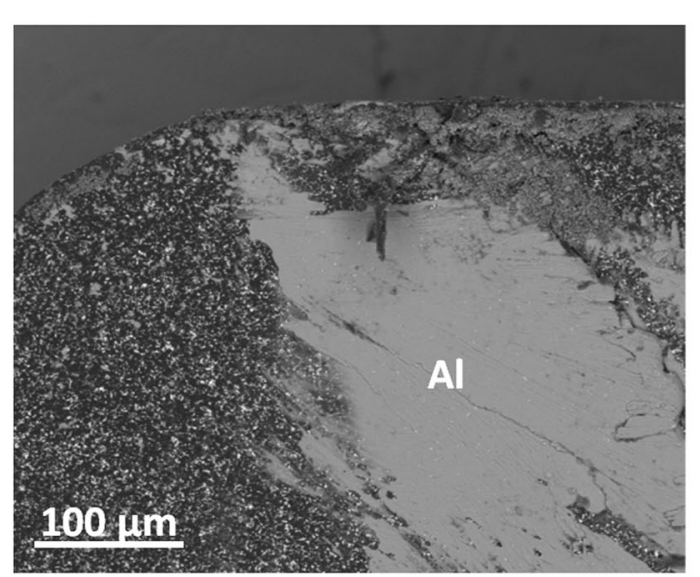

(h) 
Fig. 9 Optical microscopy images of soften chips adhered into the textures at a cutting length of $2.758 \mathrm{~km}$ : a grooves perpendicular to CFD and $\mathbf{b}$ grooves parallel to $\mathrm{MCE}$

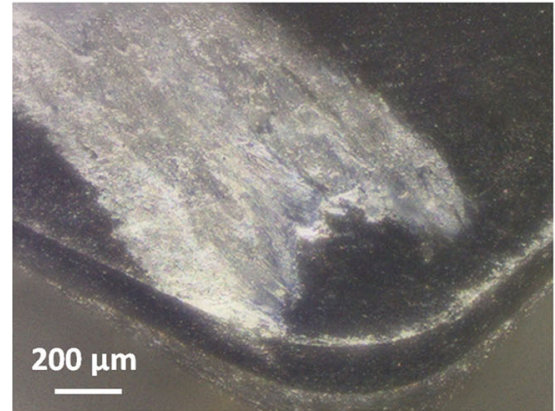

(a)

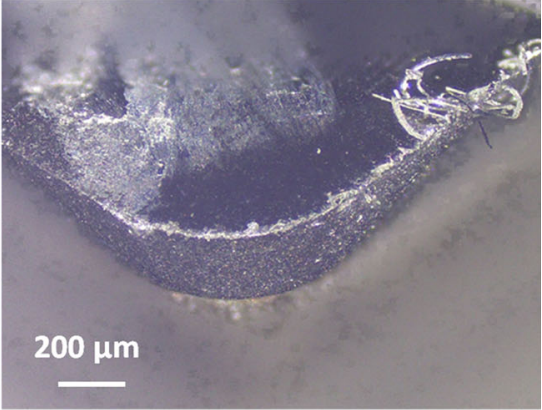

(b)
$10.2 \mu \mathrm{m})$. This is in agreement with results previously reported [29] which revealed that machining with nanotextured tool with perpendicular waviness produced smooth chips, while periodic chip patterns were created while using tool with parallel waviness. The result can be attributed to the formation of chips with different morphology (i.e. degree of segmentation, chip thickness, length) and considering that manufacturing the grooves parallel to the chip flow direction destroys the cutting edge's integrity which is responsible for the worsening of the machined quality of surface, as it was also well in line with the literature [32]. This revealed that the tool with grooves parallel to CFD can be effective in reducing the cutting forces, adhesion and friction coefficient; however, it cannot reduce the surface roughness of the machined workpiece, making it suitable for roughing application rather than finishing. This result is well in accordance with the findings of previous research applied on cemented carbide tools [41, 42] .

\section{Conclusions}

Geometrically different micro-features were manufactured via a laser process to improve cutting performance in machining Al 6082 using an optimised laser manufacturing process. The cutting performance of benchmark and textured tools was evaluated by condition monitoring of cutting forces, calculation of friction coefficients, measurement of workpiece adhesion on the cutting tool rake face and investigation of machined surface quality in dry cutting. The results showed an improvement of anti-adhesive effects in dry turning using inserts with textured grooves parallel to CFD. The thrust force for tools with grooves parallel and perpendicular to CFD showed a homogeneous trend: they fluctuated between 60 and75 N, while the benchmark ones ranged between 73 and $90 \mathrm{~N}$. Condition monitoring of thrust,
Fig. 10 Workpiece surface roughness for benchmark and textured tools

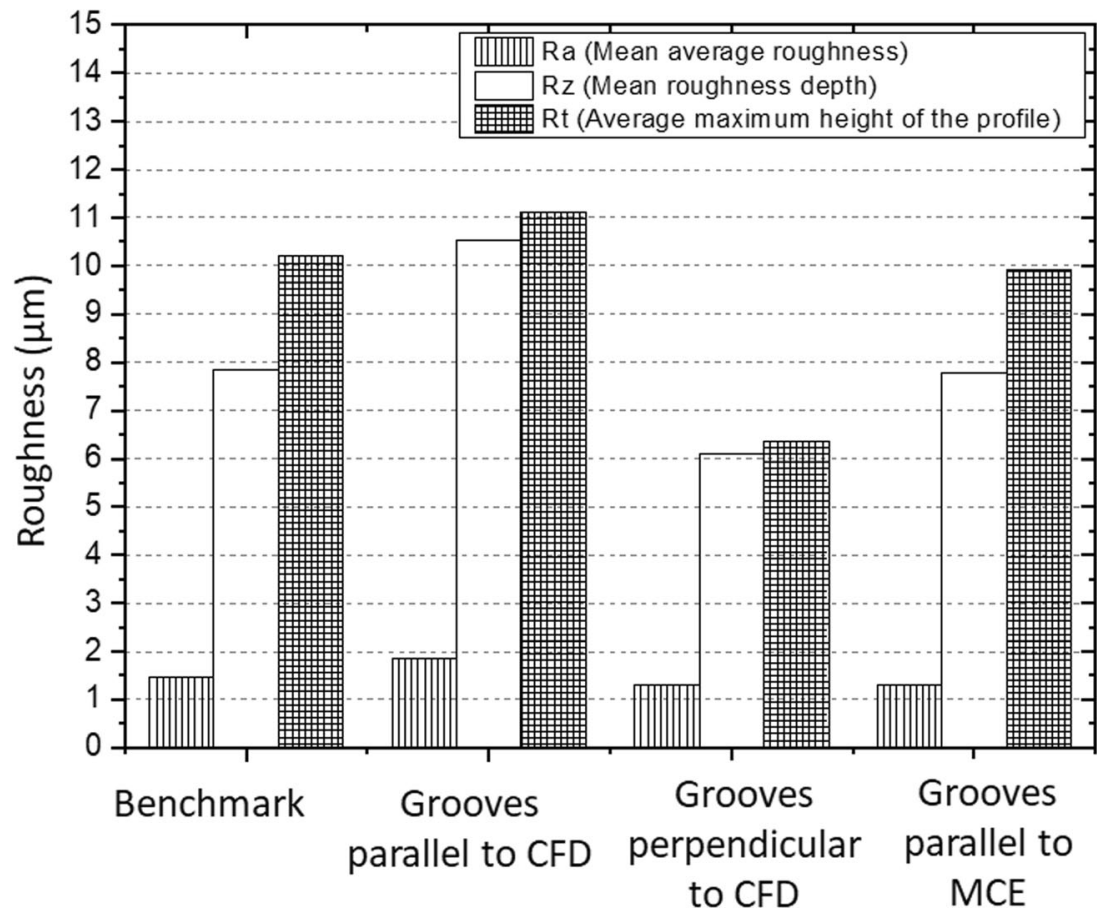


feed and radial forces showed a reduction of friction coefficient when using lasered inserts with grooves parallel to CFD as well as the lowest extent of Al 6082 stiction on the rake face. For the tool with grooves perpendicular to CFD, the coefficient of friction was calculated to be in the range $0.3-0.5$ (in $25-75 \%$ of the cases); however, the overall range of friction coefficient was found to be higher than the benchmark. This was also confirmed by EDX/SEM chemical analysis which showed that the chips resulting from both the benchmark and the textured tools with grooves perpendicular to CFD were more easily adhered to the rake face. The parts machined with cutting tools having grooves perpendicular to CFD revealed the lowest values of $\mathrm{Ra}$, $\mathrm{Rz}$ and Rt, respectively, $1.2963 \mu \mathrm{m}, 6.1055 \mu \mathrm{m}$ and $6.3592 \mu \mathrm{m}$. On the other hand, the tool with grooves parallel to CFD resulted in increased values of roughness at the workpiece. In this case, it was more difficult for the chips to easily flow into the rake face, and the formation of a BUE resulted in increased surface roughness.

The experiments carried out in this paper revealed that the mechanism for chip formation and chip flow in turning operation via PCD tools would depend on the structures and the direction of the grooves. In particular, the textured tool with grooves perpendicular to the chip flow direction proved to be the most effective in improving the cutting performance among the developed cutting tools: the cutting forces were reduced by $23 \%$, and the surface quality of the machined workpiece was improved by $11.8 \%$, making this geometry the preferred choice for finishing applications.

Manufacture of grooves parallel to CFD in Polycrystalline diamond tools reduced the cutting forces by $11.76 \%$, adhesion by $59.36 \%$ and friction coefficient by $14.28 \%$; however, it increased the surface roughness of the machined workpiece, making this suitable to enhance tool life of polycrystalline diamond tools in roughing operation while machining aluminium alloys (6082).

For the first time, laser manufacturing is proposed as a flexible technique to functionalise the geometrical and wear properties of polycrystalline diamond cutting tools to the specific applications (i.e. roughing, finishing) as opposed to the standard industrial approach to use microstructurally different PCDs (i.e. grain size and binder \%) based on type of operation. This opens new avenues for the applicability of laser technology to precision machining industries to increase productivity and reduce costs.

Acknowledgements The authors would like to acknowledge the support of Element Six Ltd. for providing the polycrystalline diamond materials.
Open Access This article is licensed under a Creative Commons Attribution 4.0 International License, which permits use, sharing, adaptation, distribution and reproduction in any medium or format, as long as you give appropriate credit to the original author(s) and the source, provide a link to the Creative Commons licence, and indicate if changes were made. The images or other third party material in this article are included in the article's Creative Commons licence, unless indicated otherwise in a credit line to the material. If material is not included in the article's Creative Commons licence and your intended use is not permitted by statutory regulation or exceeds the permitted use, you will need to obtain permission directly from the copyright holder. To view a copy of this licence, visit http://creativecommons.org/licenses/by/4.0/.

\section{References}

1. Starke EA, Staley JT (2010) Application of modern aluminium alloys to aircraft. Fundamentals of Aluminium Metallurgy: Prog Aerospace Sci 32(2):131-172

2. Mehta DS, Masood SH, Song WQ (2004) Investigation of wear properties of magnesium and aluminium alloys for automotive applications. J Mater Process Technol 155-156:1526-1531

3. Davis JR (2001) Light metals and alloys. Alloy Underst Basics: ASM International 351-416

4. Pacella M, St. John MGJ, Dolatabadi N, Badiee A (2019) Microhardness and wear behaviour of polycrystalline diamond after warm laser shock processing with and without coating. Int $\mathrm{J}$ Refract Met Hard Mater 82:215-226

5. Kalyan C, Samuel GL (2015) Cutting mode analysis in high speed finish turning of AlMgSi alloy using edge chamfered PCD tools. J Mater Process Technol 216:146-159

6. Sugihara T, Enomoto T (2009) Development of a cutting tool with a nano/micro-textured surface-improvement of anti-adhesive effect by considering the texture patterns. Precis Eng 33:425-429

7. Xing Y, Deng J, Wang X (2016) Experimental assessment of laser textured cutting tools in dry cutting of aluminum alloys. J Manuf Sci Eng 138:1-10

8. Byrne G, Dornfeld D, Denkena B (2003) Advancing cutting technology. CIRP Ann - Manuf Technol 52(2):483-507

9. Nouari M, List G, Girot F, Coupard D (2003) Experimental analysis and optimisation of tool wear in dry machining of aluminium alloys. Wear 255:1359-1368

10. Krolczyk GM, Nieslony P, Maruda RW, Wojciechowski S (2017) Dry cutting effect in turning of a duplex stainless steel as a key factor in clean production. J Clean Prod 142:3343-3354

11. Ma J, Duong H, Lian Y, Lei S (2013) Assessment of microgrooved cutting tool in dry machining of AISI 1045 steel: a numerical study. ASME Int Mech Eng Congr and Expo. Proc (IMECE) 2B:1-6

12. Sharma AK, Tiwari AK, Dixit AR (2016) Effects of minimum quantity lubrication (MQL) in machining processes using conventional and nanofluid based cutting fluids: a comprehensive review. J Clean Prod 127:1-18

13. Eberle G, Dold C, Wegener K (2015) Laser fabrication of diamond micro-cutting tool-related geometries using a high-numerical aperture micro-scanning system. Int J Adv Manuf Technol 81:11171125

14. Vijayabhaskar S, Rajmohan T, Pranay Sisir TV (2018) Review of WEDM studies on metal matrix composites. IOP Conf Ser Mater Sci Eng 390:287-291

15. Saketi S, Odelros S, Östby J, Olsson M (2019) Experimental study of wear mechanisms of cemented carbide in the turning of Ti6Al4V. Materials (Basel) 12:2822 
16. Krolczyk GM, Maruda RW, Krolczyk JB et al (2019) Ecological trends in machining as a key factor in sustainable production - a review. J Clean Prod 218:601-615

17. Schultheiss F, Fallqvist M, M'Saoubi R (2013) Influence of the tool surface micro topography on the tribological characteristics in metal cutting-part II theoretical calculations of contact conditions. Wear 298-299:23-31

18. Fallqvist M, Schultheiss F, M'Saoubi R (2013) Influence of the tool surface micro topography on the tribological characteristics in metal cutting: part I experimental observations of contact conditions. Wear 298-299:87-98

19. Hu T, Hu L, Ding Q (2012) Effective solution for the tribological problems of Ti-6Al-4V: combination of laser surface texturing and solid lubricant film. Surf Coat Technol 206:5060-5066

20. Pacella M, Axinte DA, Butler-Smith PW, Shipway P, Daine M, Wort C (2015) An assessment of the wear characteristics of microcutting arrays produced from polycrystalline diamond and cubic boron nitride composites. J Manuf Sci Eng 138(2):210011210016

21. Pacella M, Axinte DA, Butler-Smith PW, Daine M (2014) On the topographical/chemical analysis of polycrystalline diamond pulsed laser ablated surfaces. Proc CIRP 13:387-392

22. Pacella M, Axinte DA, Butler-Smith PW, Fay MW (2014) FIB/ TEM/EELS micro/nanometric investigations of the effects of laser ablation on the diamond/binder structure in polycrystalline diamond composites. J Mater Process Technol 214(5):1153-1161

23. Fukui H, Okida J, Omori N (2004) Cutting performance of DLC coated tools in dry machining alumin um alloys. Surf Coat Technol 187:70-76

24. Sugihara T, Enomoto T (2012) Improving anti-adhesion in aluminum alloy cutting by micro stripe texture. Precis Eng 36:229-237

25. Xing Y, Deng J, Zhang K et al (2014) Effect of femtosecond laser pretreatment on wear resistance of $\mathrm{Al} 2 \mathrm{O} 3 / \mathrm{TiC}$ ceramic tools in dry cutting. Int J Refract Met Hard Mater 43:291-301

26. Fang S, Pérez V, Salán N, et al (2019) Surface patterning of cemented carbides by means of nanosecond laser. Mater Manuf Process 0:1-7

27. Deng J, Lian Y, Wu Z, Xing Y (2013) Performance of femtosecond laser-textured cutting tools deposited with WS2 solid lubricant coatings. Surf Coat Technol 222:135-143

28. Ma J, Duong NH, Lei S (2015) 3D numerical investigation of the performance of microgroove textured cutting tool in dry machining of Ti-6Al-4V. Int J Adv Manuf Technol 79:1313-1323

29. Kawasegi N, Sugimori H, Morimoto H (2009) Development of cutting tools with microscale and nanoscale textures to improve frictional behavior. Precis Eng 33(3):248-254
30. Obikawa T, Kamio A, Takaoka H, Osada A (2011) Micro-texture at the coated tool face for high performance cutting. Int J Mach Tools Manuf 51(12):966-972

31. Fatima A, Mativenga PT (2015) A comparative study on cutting performance of rake-flank face structured cutting tool in orthogonal cutting of AISI/SAE 4140. Int J Adv Manuf Technol 78:2097-2106

32. Xing Y, Deng J, Zhao J (2014) Cutting performance and wear mechanism of nanoscale and microscale textured Al2O3/TiC ceramic tools in dry cutting of hardened steel. Int J Refract Met Hard Mater 43:46-58

33. Sugihara T, Enomoto T (2013) Crater and flank wear resistance of cutting tools having micro textured surfaces. Precis Eng 37:888896

34. Field JE, Pickles CSJ (1996) Strength, fracture and friction properties of diamond. Diam Relat Mater 5(6-8):625-634

35. Kümmel J, Gibmeier J, Müller E et al (2014) Detailed analysis of microstructure of intentionally formed built-up edges for improving wear behaviour in dry metal cutting process of steel. Wear 311:2130

36. Kümmel J, Braun D, Gibmeier J (2015) Study on micro texturing of uncoated cemented carbide cutting tools for wear improvement and built-up edge stabilisation. J Mater Process Technol 215:62-70

37. Flack D (2011) NPL good practice guide 42: CMM verification issue 2:1-101

38. Zhang GE, Zhang B, Deng Z, Chen JF (2007) An experimental study on laser cutting mechanisms of polycrystalline diamond compacts. CIRP Ann - Manuf Technol 56(1):201-204

39. Pacella M, Nekouie V, Badiee A (2019) Surface engineering of ultra-hard polycrystalline structures using a nanosecond $\mathrm{Yb}$ fibre laser: effect of process parameters on microstructure, hardness and surface finish. J Mater Process Technol 266:311-328

40. El-Gallab M, Sklad M (1998) Machining of Al/SiC particulate metal-matrix composites part I: tool performance. J Mater Process Technol 83:151-158

41. Franzen V, Witulski J, Brosius A et al (2010) Textured surfaces for deep drawing tools by rolling. Int J Mach Tools Manuf 50:969-976

42. Xie J, Luo MJ, He JL et al (2012) Micro-grinding of micro-groove array on tool rake surface for dry cutting of titanium alloy. Int $\mathrm{J}$ Precis Eng Manuf 13:1845-1852

Publisher's note Springer Nature remains neutral with regard to jurisdictional claims in published maps and institutional affiliations. 